\title{
Impact of cyanotic heart disease on school performance
}

\author{
$M$ Wright, $\mathrm{T}$ Nolan
}

\begin{abstract}
Surgical correction greatly decreases the mortality and cardiac morbidity of cyanotic congenital heart disease, but children remain at risk of long term difficulties in other areas. A historical cohort study was conducted to determine the relation between heart disease and school performance in 29 children aged 7 to 12 years old with simple transposition of the great arteries or tetralogy of Fallot. All children had surgical correction of their lesion before 2.5 years of age. Those at greater risk of school difficulties because of recognised complications of their heart disease or for reasons other than directly attributable to the heart disease were excluded. Comparison was made with 36 children who had presented with cardiac murmurs at a similar age, but who did not require treatment. Children with cyanotic disease showed significantly poorer performance in all academic areas assessed by the Wide Range Achievement Test-Revised; the difference in group mean score (adjusted for differences in maternal education, sex, and parental occupational prestige) for reading was $10 \cdot 3$ points (confidence interval (CI) 1.25 to $19 \cdot 34$ ), for spelling 7.8 (CI 1.11 to 14.52), and for arithmetic 6.8 (CI 0.19 to 13.39). The differences in adjusted group means for the Wechsler Intelligence Scale for Children - Revised full scale, performance and verbal IQs were significant, particularly the later at 10.1 points (CI 2.59 to $17 \cdot 61$ ). Teacher reports indicated significant differences in arithmetic when outcome was dichotomised to 'below grade' or 'not below grade'. There were no significant associations between outcome measures and the medical or perioperative parameters, however, including those related to hypoxia. It is concluded that the increased incidence of academic problems and the nature of the cognitive difficulties in children with uncomplicated corrective cardiac surgery for cyanotic heart disease are not fully explained by chronic hypoxia, or by other factors related to the cardiac surgery.

(Arch Dis Child 1994; 71: 64-70)
\end{abstract}

Cyanotic congenital heart disease has a birth prevalence of approximately $2 / 1000 .^{1}$ The primary structural lesions are varied; tetralogy of Fallot and transposition of the great arteries are the most common, accounting for about $80 \%$ or more of cases. Continuing improvements in operative and medical management have seen cumulative survival rates increase dramatically in the last 30 years. ${ }^{2}$ Because these children are being operated on at an earlier age with the expectation of a 'normal' duration and quality of life, it is particularly important to determine adverse outcomes which supervene despite early normalisation of their cardiopulmonary state.

An important, but often unrecognised concomitant of childhood illness is poor school performance, ${ }^{34}$ a risk that is greatest when the central nervous system has been involved. ${ }^{5}$ There is evidence to suggest that children with cyanotic heart disease are at particular risk because of factors specific to their illness - chronic hypoxia, anaesthetic, and surgery conditions. ${ }^{6-12}$ Most studies, however, have focused on IQ, failing to examine functional measures of long term outcome (such as school performance), or have simply assumed hypoxia to be the major contributing factor $^{6-11} 13-16$ when the actual effects of chronic (compared with acute) hypoxia on the developing human nervous system are not well known. Neuropsychological and behavioural findings suggested as evidence for the effects of chronic hypoxia have had to be drawn mainly from the study of children with acute perinatal hypoxia and adults with chronic obstructive airways disease. ${ }^{1017}$ Such data suggest that vigilance and attention are decreased, and the processing of information inhibited. As a result, some subscales of IQ tests such as the Wechsler Intelligence Scale for Children Revised (WISC-R), such as arithmetic, digit span, and coding, would be affected more than others, as would neuropsychological tests focusing on processing and behavioural measures that are particularly influenced by decreased attention.

The aim of this study was to assess school performance, using a comprehensive set of validated measures with information from multiple sources, in children who had had a corrective operation for cyanotic heart disease and who were not otherwise expected to be at significantly greater risk of having school difficulties. It was hypothesised that (a) children with cyanotic heart disease would have significantly worse academic performance than controls, (b) there would be strong associations with the duration and severity of preoperative hypoxia and perioperative factors, and (c) the nature of cognitive deficits and behavioural problems would be related to hypoxia.

Correspondence to:

Dr Martin Wright,
University of Melbourne

Department of Paediatrics,

Parkville, Victoria, Australia

3052.

Accepted 17 March 1994 
Methods

CASES

This study was approved by the Royal Children's Hospital human ethics committee. Cardiac surgery records at the Royal Children's Hospital, Melbourne (the only paediatric cardiac surgery facility in the state of Victoria, which has a population of 4.4 million) were used to obtain the names and clinical details of all children who had had a corrective operation for tetralogy of Fallot or transposition of the great arteries between February 1979 and February 1984. Comparable surgical and anaesthetic support was provided throughout this time, with all the transposition of the great arteries children having Senning procedures.

Other eligibility criteria were (a) only small to moderate sized ventricular septal defects in association with tetralogy of Fallot and a patent ductus arteriosus and/or no to small ventricular septal defect in those with transposition of the great arteries, (b) age less than 2.5 years at the time of the corrective operation (and therefore between 6 and 12 years of age when studied, in at least their second year of school), (c) residence in Victoria at the time of the study, (d) gestation greater than 33 weeks and birth weight greater than $2000 \mathrm{~g}$, (e) no significant perinatal problems such as birth asphyxia or seizures, (f) no non-cardiac clinical malformations, ( $g$ ) no evidence of postnatal neurological impairment including cerebrovascular accident or other complications of the heart condition or its treatment, (h) normal cardiopulmonary function (postoperative oxygen saturation greater than $92 \%$ and able to participate in daily activities without symptoms or requiring drugs active on the cardiovascular system), and (i) at least one parent and child English speaking.

\section{CONTROLS}

Computerised outpatient lists were used to obtain the names and details of children seen in cardiology outpatients at the Royal Children's Hospital between February 1979 and 1984, in whom the diagnosis was of either an innocent murmur or a small ventricular septal defect subsequently closing spontaneously and not requiring treatment. The same eligibility criteria were used. The control sample base will have differed from that of the cases as children with minor cardiac lesions and coming from higher socioeconomic status families would have been more likely to be seen in private rooms than referred to the cardiology patients.

It was hoped that, by using children with functional murmurs or insignificant cardiac lesions, control for some of the psychological effects of diagnosis of a cardiac disorder in a young child would be possible, while allowing consideration of medical and surgical parameters that had been hypothesised as associations with adverse outcomes. The controls used were therefore not 'normal' in terms of early environmental factors.
ENROLMENT

Contact was attempted with potential cases and controls by letter and then by telephone if there was no reply within two weeks. The Department of Social Security was used to pass on letters to families that could not be contacted, and who were on their records as receiving a government allowance. For those agreeing to participate, informed consent was obtained, questionnaires mailed to parents and teachers, and the child seen for one three hour session at the Royal Children's Hospital.

\section{MEASURES}

Parents provided information including parental age, education, and occupation, and whether they felt their child had been affected by his or her heart condition academically, physically, socially, or behaviourally. They also listed childhood illnesses and developmental milestones, which were verified where possible using the hospital records. Parents completed the child behaviour checklist (CBCL), which was used to obtain behavioural ratings, ${ }^{18}$ and the teachers completed the teacher's report form (TRF). ${ }^{19}$

Teachers indicated whether the child had been referred for extra assistance at school or repeated a grade, and gave a subjective assessment of their current level of academic performance compared with the others in the grade (on a five point Likert scale). The children were seen by a psychologist, blinded to their case status, who administered the Wide Range Achievement Test - Revised (WRAT-R) as a measure of academic achievement, ${ }^{20}$ and the full WISC-R (both standardised with mean 100 and SD 15 points). ${ }^{21}$ They were also seen by a paediatrician (not blinded to their case status, but using a standardised score sheet) who examined for neurological abnormalities $^{22}$ and residual cardiovascular signs. He also administered the self perception profile for children (a measure of a number of domains of self perception completed by the child), ${ }^{23}$ the Corsi block span (a test of short term visual memory in which there is no contamination by the use of verbal memory, as the layout of the cubes inhibits numbering and subvocalisation by the child), ${ }^{24}$ the Rey auditory verbal (RAV) learning test (through the recall of a wordlist repeatedly read out, assessing short term auditory memory and processing skills in a manner more specific to the learning environment than a digit span), ${ }^{25} 26$ the Rey figure visual (RFV) learning test (a test of perceptual organisation and visual memory in which the child is firstly asked to copy a drawing of a complex shape, and then later draw the shape from memory),, 25 and selected subtests from the Bruininks-Oseretsky test of motor proficiency, examining fine and gross motor abilities and visuomotor performance. ${ }^{28}$ After the session, parents were sent a written report of the findings which summarised their child's performance, indicating areas of concern. Follow up was offered through the department of psychology at the Royal Children's Hospital. 
Table 1 Baseline characteristics

\begin{tabular}{|c|c|c|}
\hline & $\begin{array}{l}\text { Cases } \\
(n=29)\end{array}$ & $\begin{array}{l}\text { Controls } \\
(n=36)\end{array}$ \\
\hline \multicolumn{3}{|l|}{ Age at assessment (months) } \\
\hline Mean (SD) & $114(14)$ & $113(14)$ \\
\hline Range & 84-137 & $89-135$ \\
\hline No $(\%)$ boys & $20(69)$ & $20(56)$ \\
\hline \multicolumn{3}{|l|}{ Gestation (weeks) } \\
\hline Mean (SD) & $39 \cdot 3(1 \cdot 6)$ & $39 \cdot 6(2 \cdot 4)$ \\
\hline Range & $36-43$ & $33-43$ \\
\hline \multicolumn{3}{|l|}{ Birth weight (g) } \\
\hline Mean (SD) & $3245(640)$ & $3341(600)$ \\
\hline Range & $2270-4470$ & $2041-4950$ \\
\hline Mean (SD) occupational prestige* & $4 \cdot 5(1 \cdot 2)$ & $5(1 \cdot 1)$ \\
\hline Maternal education (percentage less than 11 years) & 55 & 50 \\
\hline \multicolumn{3}{|l|}{ Maternal age at assessment (years) } \\
\hline Mean (SD) & $37(3 \cdot 7)$ & $35(4 \cdot 8)$ \\
\hline Range & $26-43$ & $26-48$ \\
\hline Marital status (No (\%) single parent) & $2(7)$ & $6(16)$ \\
\hline
\end{tabular}

${ }^{\star}$ Lower score equals greater prestige.

\section{ANALYSIS}

Analysis was performed using the SAS statistical package. ${ }^{29}$ Basic comparative analyses used the $\chi^{2}$ test (or Fisher's exact test), and a $t$ test for independent samples for outcomes expressed as proportions and continuous scores respectively. Standardised effect sizes were calculated for continuous outcomes to further aid comparison of the two groups. Risk ratios (RR) and 95\% confidence intervals, with the control group as the denominator, were calculated for proportions where appropriate. Where continuous scores such as the CBCL did not conform to a normal distribution, adjusted means were compared using non-parametric bivariate analysis with the Wilcoxon two sample test. Linear multiple regression was used to determine potential confounders and adjustment was made for gender, socioeconomic status (operationalised as parental occupational prestige), ${ }^{30}$ and maternal education using analysis of covariance (ANCOVA). ANCOVA was also used to adjust for differences in age distribution when the test results were not standardised (for example, digit span and self perception). Bivariate correlations and their 95\% confidence intervals (CIs) were determined with major outcomes as the dependent variables and medical and surgical parameters as the independent variables.

\section{Results}

In total, 42 children fulfilled the entry requirements from the information available in their cardiac surgery and hospital records. Of these, 40 could be contacted. Parents of seven children refused consent and a further

Table 2 Results from the WRAT-R. Values are mean (SD) values

\begin{tabular}{|c|c|c|c|c|}
\hline & $\begin{array}{l}\text { Cases } \\
(n=29)\end{array}$ & $\begin{array}{l}\text { Controls } \\
(n=36)\end{array}$ & p Value & $\begin{array}{l}95 \% \text { CI for difference } \\
\text { in adjusted means }\end{array}$ \\
\hline \multicolumn{5}{|l|}{ Reading } \\
\hline Crude & $82.9(18.49)$ & $93.6(18.45)$ & & \\
\hline Adjusted $^{\star}$ & $83.9(17 \cdot 77)$ & $94.2(18.50)$ & 0.026 & 1.25 to 19.34 \\
\hline \multicolumn{5}{|l|}{ Spelling } \\
\hline Crude & $81 \cdot 0(12 \cdot 27)$ & $89.5(14.64)$ & 0.023 & 1.11 to 14.52 \\
\hline \multicolumn{5}{|l|}{ Arithmetic } \\
\hline $\begin{array}{l}\text { Crude } \\
\text { Adjusted }\end{array}$ & $\begin{array}{l}88.1(13.38) \\
88.6(12.96)\end{array}$ & $\begin{array}{l}95.5(11.82) \\
95.4(13.49)\end{array}$ & 0.044 & 0.19 to 13.39 \\
\hline
\end{tabular}

*Adjusted for group differences in socioeconomic status, gender and maternal education. Note: WRAT-R norms are standardised to mean $=100, S D=15$. four were excluded when information about disorders not managed at the Royal Children's Hospital was available from the parental questionnaires. One had a history of three focal seizures not temporally related to the cardiac operation, one had required bilateral leg callipers for the first three years of life due to bilateral upper motor neuron damage, one had pneumococcal meningitis a number of years after the operation, and the other had developed a right hemiplegia after the cardiac operation. Therefore 29/38 (76\%) were included. Those who refused or were unable to be contacted may not all have fulfilled entry criteria, but were of similar age when the study was performed and at the corrective operation. Of this group, six $(66 \%)$ had tetralogy of Fallot and eight (89\%) were boys, $v 12(41 \%)$ and $20(69 \%)$ in the final study group. These differences were not statistically significant $(\mathrm{p}=0.15$ and 0.24 respectively).

Contact was made with 45 of 80 controls, of whom 41 consented to the study. Five of these were excluded when further information from the parents indicated insufficient English (four) or that the child had a persistent symptomatic cardiac defect requiring ongoing treatment (one). Table 1 gives the baseline characteristics of the two groups. The greater number of boys in the case group was partly related to the greater incidence of transposition of the great arteries in boys (approximately $2 \cdot 3$ to 1 , boys to girls). The mean (SD) haemoglobin concentration and oxygen saturation recorded before and closest to the time of the corrective operation were $162(31.0) \mathrm{g} / \mathrm{l}$ and 84 $(9 \cdot 4) \%$ respectively. The cases were between 4 and 120 weeks old when operated on (mean 45.7 weeks), 20 of them having had earlier palliative surgery. The mean (SD) duration of cardiac bypass and cardiac arrest were $61(16 \cdot 7)$ and $39(7 \cdot 5)$ minutes respectively.

\section{ACADEMIC OUTCOME}

When adjusted for differences in maternal education, socioeconomic status, and sex, the cases performed significantly worse than the controls in all three of the subscales of the WRAT-R (table 2). WRAT-R reading, spelling, and arithmetic group mean scores were on the 13th, 12 th, and 21 st centiles for the cases and on the 34th, 25th, and 37th centiles for the controls. Approximate standardised effect sizes were moderately large, between 0.5 and 0.6 . When further adjustment was made for differences in full scale IQ, these differences were lessened and became statistically non-significant. The teacher ratings of school performance were stratified into 'below grade level' or 'at or above grade level' and the two groups compared. There was a significant difference in arithmetic $(p=0.03)$, but not reading or spelling. Eight $(28 \%)$ of the cases and only four $(11 \%)$ of the controls had been referred for extra assistance at school $(p=0.114 ; R R$ $2 \cdot 48$; CI 0.81 to $7 \cdot 58$ ). Two of the cases and one control were reported to have repeated a grade. Ten of the 29 teachers of the cases 
Table 3 Bivariate correlations between medical and perioperative parameters, and $I Q$ and $W R A T-R$ reading performance

\begin{tabular}{llll}
\hline Dependent variable & Independent variable & r Value & 95\% CI for $\mathrm{r}$ \\
\hline WISC-R full scale IQ & Age at operation & -0.07 & -0.42 to 0.31 \\
& Duration of cardiac bypass & -0.26 & -0.58 to 0.11 \\
& Duration of cardiac arrest & -0.36 & -0.68 to 0.07 \\
& Temperature for operation & -0.10 & -0.45 to 0.28 \\
& Duration of rewarming & 0.28 & -0.10 to 0.58 \\
& Oxygen tension $\dagger$ & 0.05 & -0.48 to 0.54 \\
& Oxygen saturation $\ddagger$ & 0.26 & -0.17 to 0.61 \\
& pHS & 0.05 & -0.45 to 0.53 \\
WRAT-R reading & Haemoglobin & -0.02 & -0.69 to 0.35 \\
& Age at operation & -0.01 & -0.55 to 0.36 \\
& Duration of cardiac bypass & -0.16 & -0.37 to 0.22 \\
& Duration of cardiac arrest ${ }^{\star}$ & -0.41 & -0.70 to 0.02 \\
& Temperature for operation & -0.10 & -0.45 to 0.27 \\
& Duration of rewarming & 0.02 & -0.35 to 0.68 \\
& Oxygen tension $\dagger$ & 0.22 & -0.33 to 0.66 \\
& Oxygen saturation $\ddagger$ & 0.16 & -0.27 to 0.54 \\
& pHS & 0.05 & -0.46 to 0.53 \\
& Haemoglobin & -0.17 & -0.51 to 0.21
\end{tabular}

$\star^{\star} n=22$ as seven cases with tetralogy of Fallot not operated under cardiac arrest.

$\mathrm{t} n=15$ because of missing data.

$\ddagger \mathrm{n}=23$ because of missing data.

$\mathrm{f} n=16$ because of missing data.

indicated that they knew the child had a cardiac disorder. Though these children tended to have lower WRAT-R reading scores than the 19 other cases, the differences were not statistically significant $(p=0 \cdot 07)$.

ASSOCIATION OF CURRENT FUNCTIONING WITH MEDICAL AND SURGICAL PARAMETERS

Simple linear regression was used with WISC-R full scale IQ and the three WRAT-R subscales separately as outcome measures to examine correlations with individual medical and surgical parameters. There was no statistically significant association with any of the medical or surgical parameters. Duration of cardiac arrest, however, approached significance and the correlation with WRAT-R reading was moderate (table 3 ).

Table 4 WISC-R scores. Values are crude means (SD) above, with adjusted means (SD) below

\begin{tabular}{|c|c|c|c|c|}
\hline & $\begin{array}{l}\text { Cases } \\
(n=29)\end{array}$ & $\begin{array}{l}\text { Controls } \\
(n=36)\end{array}$ & p Value & $\begin{array}{l}95 \% \text { CI for difference } \\
\text { in adjusted means }\end{array}$ \\
\hline \multirow[t]{2}{*}{ Information } & $10 \cdot 1(3 \cdot 80)$ & $10 \cdot 8(2 \cdot 26)$ & & \\
\hline & $9 \cdot 7(3.02)$ & $10 \cdot 8(2.91)$ & $0 \cdot 15$ & -0.41 to 2.55 \\
\hline Similarities & $7 \cdot 3(4 \cdot 60)$ & $10 \cdot 2(3.00)$ & & \\
\hline \multirow[t]{2}{*}{ Arithmetic } & $\begin{array}{l}6 \cdot 9(3 \cdot 77) \\
9 \cdot 1(3 \cdot 10)\end{array}$ & $\begin{array}{l}10 \cdot 3(3 \cdot 66) \\
10 \cdot 2(2 \cdot 80)\end{array}$ & 0.001 & 1.57 to 5.27 \\
\hline & $8.9(3.02)$ & $10.2(2.91)$ & 0.08 & -0.16 to $2 \cdot 81$ \\
\hline \multirow[t]{2}{*}{ Vocabulary } & $8.7(3.60)$ & $10 \cdot 2(2 \cdot 30)$ & & \\
\hline & $8.5(2.91)$ & $10 \cdot 3(2 \cdot 88)$ & 0.02 & 0.32 to 3.19 \\
\hline Comprehension & $\begin{array}{l}8 \cdot 6(2 \cdot 80) \\
8 \cdot 6(2 \cdot 53)\end{array}$ & $\begin{array}{l}9 \cdot 6(2.40) \\
9 \cdot 7(2.46)\end{array}$ & 0.09 & -0.17 to 2.31 \\
\hline \multirow[t]{2}{*}{ Digit span ${ }^{\star}$} & $8 \cdot 1(2 \cdot 80)$ & $8 \cdot 7(2 \cdot 70)$ & & \\
\hline & $8 \cdot 2(3 \cdot 77)$ & $8 \cdot 7(2 \cdot 76)$ & 0.55 & $-1 \cdot 18$ to $2 \cdot 18$ \\
\hline Picture completion & $9.4(2.50)$ & $10 \cdot 0(2 \cdot 80)$ & & \\
\hline \multirow[t]{2}{*}{ Picture arrangement } & $\begin{array}{l}9.3(2.85) \\
9.8(3.30)\end{array}$ & $\begin{array}{r}10.0(2.76) \\
9.9(2 \cdot 70)\end{array}$ & 0.34 & -0.73 to 2.06 \\
\hline & $\begin{array}{r}9.9(3 \cdot 18) \\
11 \cdot 1(3.70)\end{array}$ & $\begin{array}{l}10.0(3.06) \\
12.6(3.40)\end{array}$ & $0 \cdot 89$ & -1.47 to 1.68 \\
\hline Block design & $10.7(3.57)$ & $12.5(3.44)$ & 0.04 & 0.09 to 3.60 \\
\hline Object assembly & $10 \cdot 8(3.90)$ & $12.4(3.30)$ & & \\
\hline \multirow[t]{2}{*}{ Coding } & $\begin{array}{r}10.5(3.72) \\
8.5(2.60)\end{array}$ & $\begin{array}{l}12.4(3.60) \\
10 \cdot 2(3.40)\end{array}$ & 0.04 & 0.06 to 3.73 \\
\hline & $\begin{array}{c}8 \cdot 4(3.23) \\
92 \cdot 2(19 \cdot 60)\end{array}$ & $\begin{array}{c}10 \cdot 0(3 \cdot 12) \\
100 \cdot 6(12 \cdot 10)\end{array}$ & 0.04 & 0.05 to 3.20 \\
\hline Verbal scale IQ & $90 \cdot 8(15 \cdot 29)$ & $100 \cdot 9(14 \cdot 76)$ & 0.009 & 2.59 to 17.61 \\
\hline \multirow{2}{*}{ Performance scale IQ } & $99 \cdot 4(17 \cdot 20)$ & $106 \cdot 9(14 \cdot 40)$ & & \\
\hline & $\begin{array}{l}98.2(16.59) \\
95.2(18.90)\end{array}$ & $\begin{array}{l}106 \cdot 5(16 \cdot 02) \\
103 \cdot 8(12 \cdot 10)\end{array}$ & 0.05 & $0 \cdot 11$ to $16 \cdot 41$ \\
\hline Full scale IQ & $93.8(15.67)$ & $103.8(15.12)$ & 0.01 & $2 \cdot 32$ to $17 \cdot 72$ \\
\hline
\end{tabular}

^Data available for only 16 of the cases for digit span.

Note: WISC-R norms are standardised to mean $=100, S D=15$

Values adjusted for differences between the two groups in gender, maternal education, and occupational prestige.

\section{COGNITIVE OUTCOME}

There were statistically and clinically significant differences between the group means in full scale IQ, performance IQ, verbal IQ, and in similarities, vocabulary, block design, object assembly, and coding subscales (table 4). In all, the difference in adjusted means was greater than half a standardised standard deviation, and the full scale IQ difference represents a moderate to large effect size of two thirds. Using a paired $t$ test for both cases and controls, verbal scores were significantly lower than performance scores $(p=0.007$, CI $2 \cdot 2$ to $12 \cdot 3$ for the cases; and $p=0 \cdot 02$, CI $1 \cdot 0$ to $11 \cdot 5$ for the controls).

\section{SHORT TERM MEMORY}

ANCOVA was used to adjust for differences in distribution of age as well as socioeconomic status, sex, and maternal education. Using the maximum number of digits retained forward from the digit span subtest of the WISC-R, there was no significant difference in short term auditory memory $(p=0.80 ; C I-0.33$ to $0 \cdot 47$ ). ANCOVA was also performed using the number of blocks retained in the Corsi block span test. There was no significant difference $(p=0.68 ; C I-0.35$ to 0.53$)$.

\section{BEHAVIOUR/ADJUSTMENT}

There was a significant difference between the two groups in the maladjustment rate recorded by the parents $(p=0.015$; CI for the difference in percentages $5 \%$ to $49 \%$ ) and the parents of the cases were more likely to believe that the cardiac disorder had affected their child behaviourally $(p=0.035)$, but not in the other areas (table 5). The maladjustment rate for the cases was significantly higher than the North American test norms $(p<0.001)$. Although there was no significant difference in any of the major and narrow band scales other than hyperactive $(p=0.03)$, the cases scored higher in all but one narrow band scale. There was no difference between cases and controls in teacher reported incidence of maladjustment, both were similar to the North American norms, and there was no significant difference in the narrow or broad band scales of the TRF.

\section{SELF PERCEPTION}

Using ANCOVA for each of the six subscales in the Harter, there was no significant difference between cases and controls. When the cases were grouped into those performing greater than 1 SD below the WRAT-R reading mean, and those doing better, the former group rated themselves significantly lower for scholastic perception only $(p=0.04$; CI for differences in adjusted means 0.4 to 9.55 ).

MOTOR AND NEUROLOGICAL EXAMINATION All the controls had a normal peripheral neurological examination. Five cases $(17 \%)$ had mildly and symmetrically increased reflexes, without abnormalities of tone or 
Table $5 \quad C B C L$ and TRF major scales and maladjustment rates. Values are crude means (SD) above and adjusted means (SD) below for the CBCL

\begin{tabular}{|c|c|c|c|c|}
\hline Scale $^{\star}$ & Cases & Controls & $p$ Value $†$ & $\begin{array}{l}95 \% \text { Confidence } \\
\text { interval (CI) }\end{array}$ \\
\hline \multicolumn{5}{|l|}{ CBCL } \\
\hline Summary $\mathbf{T}$ & \multirow{6}{*}{$\begin{array}{l}58.9(10.8) \\
59.2(11.8) \\
58.6(10.4) \\
59.5(11.6) \\
58.3(10.2) \\
58.5(11.1) \\
41\end{array}$} & \multirow{6}{*}{$\begin{array}{l}54 \cdot 9(10 \cdot 1) \\
55 \cdot 8(10 \cdot 7) \\
54 \cdot 7(10 \cdot 9) \\
54 \cdot 5(10 \cdot 8) \\
54 \cdot 2(9 \cdot 5) \\
54 \cdot 2(10 \cdot 1) \\
14\end{array}$} & \multirow[b]{2}{*}{$0 \cdot 11$} & \multirow[b]{2}{*}{$-2 \cdot 2$ to $9 \cdot 0$} \\
\hline Internalising & & & & \\
\hline & & & \multirow{2}{*}{0.08} & \multirow{2}{*}{-0.6 to 10.6} \\
\hline Externalising & & & & \\
\hline & & & \multirow[t]{2}{*}{$0 \cdot 10$} & \multirow{2}{*}{-1.0 to 9.6} \\
\hline $\begin{array}{l}\text { Maladjustment rate } \\
\text { TRF }\end{array}$ & & & & \\
\hline Summary $\mathrm{T}$ & $49 \cdot 7(9 \cdot 6)$ & $52 \cdot 1(8 \cdot 5)$ & $0 \cdot 30$ & -2.1 to 6.9 \\
\hline Internalising & $51.9(8.7)$ & $54 \cdot 1(8 \cdot 3)$ & $0 \cdot 30$ & $-2 \cdot 0$ to $6 \cdot 4$ \\
\hline Externalising & $50 \cdot 8(8 \cdot 2)$ & $52 \cdot 2(7.9)$ & 0.49 & $-2 \cdot 6$ to $5 \cdot 4$ \\
\hline Maladjustment rate $\ddagger$ & 14 & 14 & & \\
\hline
\end{tabular}

${ }^{\star_{n}}=29$ for cases and 35 for controls.

TThe $\mathrm{p}$ value quoted was obtained from a two tailed $t$ test on the adjusted means.

$¥$ Percentage of children with a summary behaviour problem t-score greater than one standard deviation above the mean. Rate for normative sample is $10 \%$.

For the CBCL, RR (risk ratio cases relative to controls) $=2.9 .95 \% \mathrm{CI}$ for $\mathrm{RR}=0.62$ to $4.06 . \chi^{2}$ with $1 \mathrm{DF}=5.97$ for the difference between cases and controls $(p=0.015$; CI for the difference in percentages 5 to $49 \%$ )

Note: $C B C L$ and TRF norms are standardised to mean $=50, S D=10$.

plantar reflexes. This difference was significant $(p=0.014 ; C I$ for difference in percentages 3 to $31 \%$ ). Cases performed worse on the balance subscale of the Bruininks-Oseretsky test of motor proficiency (mean (SD) adjusted score $9.0(6.6)$ for cases and $12.9(6.4)$ for controls; $\mathrm{p}=0.02$; CI for difference in adjusted means 0.55 to $7 \cdot 17$ ), used as a measure of gross motor performance, but not on the visual motor or fine motor measures.

To aid the consideration of whether the only reason for between group differences in academic and cognitive outcomes was the greater incidence of neurological impairment in the cases, and as the control group had worse motor performance than the standardisation sample, WISC-R IQ and WRAT-R scores were stratified according to the balance score (greater than or equal to $2 \mathrm{SDs}$ below the test mean or above this value).

Those with poor motor performance had an equally poor outcome whether from the case or control group (table 6). For those with higher motor scores (in all the categories having a better outcome than those from the same group with lower motor scores), the controls performed significantly better than the cases on the WRAT-R scales and the WISC-R performance scale, with effect sizes between 0.5 and $0 \cdot 75$. On the other WISC-R scales, though the

Table 6 Comparison of the WISC-R and the WRAT-R scores stratified by gross motor performance on the balance subtest of the Bruininks-Oseretsky test of motor proficiency. Values are mean (SD)

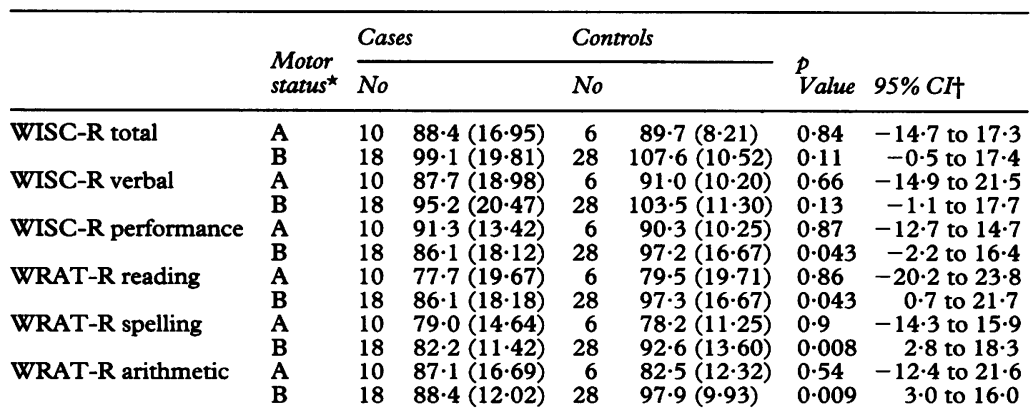

${ }^{\star} \mathrm{A}=\mathrm{Greater}$ than or equal to 2 SDs below the gross motor test mean; $B=$ less than 2 SDs below the mean.

$+95 \% \mathrm{CI}$ for the difference in means.

Note: test mean scores are 100, SD 15. differences were not statistically significant, effect sizes were between 0.5 and 0.55 .

REY LEARNING TESTS

There was no significant difference between the two groups in the RAV when the scores for the first five recalls were added $(p=0.15$; CI -1.27 to $7 \cdot 87$ ), or in the RFV recall test $(p=0 \cdot 16 ; C I-1.04$ to 6.33$)$. Differences in the RFV copy test were significant $(p=0.002$; CI $0 \cdot 17$ to $8 \cdot 55)$.

\section{Discussion}

Children who had had successful surgical correction of uncomplicated transposition of the great arteries or tetralogy of Fallot at an early age, and who did not have evidence of major nervous system trauma as a result of the cardiac lesion or its treatment, performed significantly worse in a standardised test of academic achievement than a control group of children. The children with cardiac disorders were also more likely to have been referred for extra school assistance, though this difference was not statistically significant. Although major differences in IQ were present, and adjustment of academic performance for such variance decreased the above academic differences to being not statistically significant, this may have been a reflection of the lack of statistical power of the study. Furthermore, because the control group performed below the level of the normative sample on the WRAT-R, academic performance differences could well have been greater if the control group had been taken from the general population, as they probably would have if children having a corrective operation for more severe forms of cyanotic heart disease had been eligible.

Other important findings were the lack of a statistically significant strong association between cognitive or academic outcomes and medical or perioperative parameters, as well as the lack of processing difficulties and attentional problems in the cognitive and behavioural profiles. The latter would have been suggestive of hypoxia being a major determinant of poor performance. The cases were not rated as being less attentive by their teachers on the TRF, and the TRF maladjustment rate was the same for cases and controls, yet there were significant differences between the current perceptions of the parents of children with cyanotic heart disease, the teachers of these children, and the parents of the control children. The CBCL maladjustment rates for cases and controls differed significantly, and the parents of cases were more likely to believe that the cardiac disorder had affected their child's behaviour. The maladjustment rate for cases was also significantly greater than for the normative sample.

Overall, these findings are consistent with environmental factors other than those controlled for by maternal occupation and parental occupational prestige (such as parent-child interaction) contributing to the differences in 
outcome - academic, cognitive, and behavioural. ${ }^{31}$ The differences between the two groups in neurological outcomes - gross motor performance and peripheral neurological examination - may suggest a neurological basis for the group differences in academic and cognitive performance. Although asymmetrical and mild increases in reflexes without other peripheral neurological findings is a common phenomenon in this age group, ${ }^{32}$ children with poor motor performance, regardless of group, performed worse academically and had a poorer cognitive function. Nevertheless, children with cyanotic heart disease performed worse than the controls when motor performance was within the normal range. This suggests that, whether or not due to hypoxia, birth trauma or other insult, poor motor performance in either group is similarly associated with poor cognitive and academic outcomes. When motor performance was within the normal range (and the likelihood of neurological damage was lower), the cases performed significantly worse than the controls.

This study addresses many of the methodological shortcomings of studies reported previously. These include small study sample sizes, 123334 failure to exclude children at higher risk of cognitive difficulties and school dysfunction (because of obvious neurological insult, perinatal risk factors, congenital malformations), 810333536 the use of semistructured interviews or case descriptions rather than validated measures, especially when considering emotional and behavioural responses, ${ }^{6} 3738$ limited consideration of environmental and social factors (which may have as great or greater impact on cognitive development and academic performance), ${ }^{12} 3940$ the the use of children with only one type of cardiac lesion, limiting generalisability to the majority of children with cyanotic heart disease. ${ }^{7912}$ Some studies have drawn conclusions from the examination of very young children, limiting their ability to make firm inferences about future functioning, ${ }^{4142}$ or have not used control groups. ${ }^{4143}$ Others have studied subjects with greatly variable ages, necessitating the use of different tests of cognitive and other functions, which may not be directly comparable. ${ }^{35} 4144$

The inability to separately explain the effects of decreased physical activity, parent-child interactions, and other early environmental factors is a limitation of our study, though studying a group on average younger at the time of the corrective operation lessens the impact of such factors compared with other studies. ${ }^{835}$ Because such specific information is not recorded routinely, a prospective study would be required using relevant validated measures. Furthermore, the ability of this and other studies to determine whether hypoxia is a significant contributor to adverse outcomes is constrained by the lack of availability of suitable biochemical and haematological measures which integrate fluctuations over time. ${ }^{11}$ The failure to demonstrate significant associations with these parameters may have been due to their imprecision as markers for long term hypoxia. On the other hand, though multiple sampling of oxygen saturation may have enabled a better overall estimate of chronic hypoxia, it too has not been validated for this purpose.

Control group performance on the subscales of the WRAT-R was 0.3 to 0.65 SDs below that of the normative mean, ${ }^{20}$ and motor performance was also poorer than expected. The use of this control group may therefore have resulted in a substantial underestimation of the true effect of cyanotic heart disease. Using children who had cardiac surgery for acyanotic heart disease as a third control group may have allowed the effects of cardiac surgery to be separated from those of hypoxia, though differences in surgical and anaesthetic conditions would still need to be considered.

Since the early to mid 1980 s the operation of choice for children with transposition of the arteries has been the arterial switch procedure performed within the first few days of life, unless there is a more complicated cardiac defect. This results in cardiac anatomy and function much closer to normal. Mortality and morbidity (short term at least) have improved, ${ }^{45}$ and the potential adverse effects of chronic hypoxia or physical restriction have been limited. The conclusions based on our study may therefore not apply to many children with transposition born more recently. They do apply, however, to the large number of children with surgically ameliorated transposition who are now in their middle school years and beyond. Two follow up studies have reported on the developmental, cognitive, and neurological outcome of preschool children who have undergone arterial switch procedures. Unfortunately, these studies have also not adequately considered non-medical or other surgical factors. ${ }^{46} 47$ Although there have been changes in the management of children with tetralogy, they have not been nearly as great, with an operation still performed at a much later age than for transposition.

\section{Conclusion}

Despite continuing improvements in surgical and medical management, children with cyanotic heart disease are at great risk of having difficulties at school. This includes those children without specific cardiac or noncardiac factors which are likely to predispose to a poorer outcome. Greater attention needs to be directed towards the factors influencing the long term quality of life, such as those that affect school performance. To do this, there must be continuing assessment of noncardiac outcome which takes account of changes in surgical management. This study suggests that hypoxia may not be the most important determinant of the increased school difficulties that these children experience. Further research needs to be directed towards developing a measure of chronic hypoxia and the determination of its effects on cognitive development. Research is also needed to more accurately describe the environmental 
influences on children with cyanotic heart disease.

For the practising paediatrician, there needs to be recognition that children undergoing major medical intervention in the first years of life can have important developmental problems even when the operation is successful. Vigilant monitoring of cardiac patients' academic and behavioural development, with the anticipation that counselling and tutoring may be needed, is required. In addition, these results emphasise the importance of counselling parents to recognise the special needs of their child and the importance of 'normalising' their child's existence to the greatest possible extent. Prescribed disability may be as deleterious as the consequences of the cardiac disease itself.

We gratefully acknowledge the assistance of Dr F Oberklaid in conceiving and initiating the study, $\mathrm{Mr} \mathrm{R}$ Mee in obtaining the conceiving and initiating the study, Mr R Mee in obtaining the cardiac surgery data and providing invaluable surgical information, the staff of the clinical epidemiology and biostatistics unit
in the analysis, and $\mathrm{Dr} \mathrm{V}$ Anderson for neuropsychological in the

1 Anderson RH, Macartney FJ, Shinebourne EA, et al, eds Paediatric cardiology. New York: Churchill Livingstone, 1987.

2 Morris CD, Menashe VD. 25-Year mortality after surgical repair of congenital heart defect in childhood: a population-based cohort study. $¥ A M A 1991 ; 266: 3447-52$.

3 Fowler MG, Johnson MP, Atkinson MS. Schoo achievement and absence in children with chronic health conditions. F Pediatr 1985; 106: 683-7.

4 Gortmaker SL, Walker DK, Weitzman M, Sobol AM Chronic conditions, socioeconomic risks, and behavior problems in children and adolescents. Pediatrics $1990 ; 85$ 267-76.

5 Anderson V, Godber T. Prophylactic cranial irradiation in childhood acute lymphoblastic leukaemia: neuropsychological and educational implications. $f$ Clin Exp Neuropsychol 1991; 13: 437 .

6 Linde LM, Rasof B, Dunn OJ. Mental development in congenital heart disease. 7 Pediatr 1967; 71: 198-203.

7 Wells FC, Coghill S, Caplan HL, Lincoln C, Kirklin JW. Duration of circulatory arrest does influence the psychoDuration of circulatory arrest does influence the psycho-
logical development of children after cardiac operation in early life. $\mathcal{F}$ Thorac Cardiovasc Surg 1983; 86: 823-31.

8 O'Dougherty M, Wright FS, Garmezy N, Loewenson RB, Torres F. Later competence and adaptation in infants who survive severe heart defects. Child Dev 1983; 54 1129-42.

9 O'Dougherty M, Nuechterlein KH, Drew B. Hyperactive and hypoxic children: signal detection, sustained attention and behavior. 7 Abnorm Psychol 1984; 93: 178-91.

10 O'Dougherty M, Wright FS, Loewenson RB, Torres F. Cerebral dysfunction after chronic hypoxia in children. Neurology 1985; 35: 42-6.

11 Newburger JW, Silbert AR, Buckly LP. Cognitive function and age at repair of transportation of the great arteries in and age at repair of transportation of the gred
children. NEngl f Med 1984; 310: 1495-9.

12 Hesz N, Clark EB. Cognitive development in transposition of the great arteries. Arch Dis Child 1988; 63: 198-200.

13 Feldt RH, Ewert JC, Stickler GB, Weidman WH. Children with congenital heart disease; motor development and intelligence. $A m \mathcal{F}$ Dis Child 1969; 117: 281-7.

14 Gilles FH, Leviton A, Jammes J. Age-dependent changes in white matter in congenital heart disease. 7 Neuropatho Exp Neurol 1973; 32: 179.

15 Simonson E, Winchell P. Effect of high carbon dioxide and of low oxygen concentration on fusion frequency of flicker. $\mathcal{F}$ Appl Physiol 1950-1; 3: 637-41.

16 Aisenberg RB, Rosenthal A, Wolf PH, Nadas AS Hypoxaemia and critical flicker frequency in congenital heart disease. Am $\mathcal{f}$ Dis Child 1974; 128: 335-8.

17 Robertson CMT, Finer NN, Grace MGA. School performance of survivors of neonatal encephalopathy associated with birth asphyxia at term. $\mathcal{F}$ Pediatr 1989; 114: 753-60.
18 Achenbach TM, Edelbroch C. Manual for the child behavior checklist and revised child behavior profile. Burlington, VT University of Vermont Department of Psychiatry, 1983.

19 Achenbach TM, Edelbroch C. Manual for the teacher's repor form and teacher version of the child behavior profile. Burlington, VT: University of Vermont Department of Psychiatry, 1986

20 Jastak S, Wilkinson GS. Wide range achievement test-revised. Wilmington, DE: Jastak Associates, 1978.

21 Wechsler D. Wechsler intelligence scale for children - revised. Texas: Psychological Corporation, 1974.

22 Touwen BC. Examination of the child with minor neurological dysfunction. London: Heinemann, 1979.

23 Harter S. Self perception profile for children. Denver, CO: University of Denver, 1985 .

24 Milner B, Taylor L. Right hemisphere superiority in tactile pattern recognition after cerebral commissurotomy. Evidence for nonverbal memory. Neuropsychologia 1972; 10: $1-15$.

25 Rey A. L'examen psychologique dans les cas d'encephalopathie traumatique. Archives de Psychologie 1941; 28: 21-44

26 Taylor EM. Psychological appraisal of children with cerebral defects. Cambridge, MA: Harvard University Press, 1959.

27 Osterreith P. Le test de copie d'une figure complexe. Archives de Psychologie 1944; 30: 206-356.

28 Bruininks R. Bruininks-Oseretsky test of motor proficiency. Minnesota: American Guidance Service, 1978

29 SAS Institute Inc. SAS/STAT guide for personal computers, version 6. Cary, NC: SAS Institute Inc, 1987.

30 Daniel A. Power, privilege and prestige: occupations in Australia. Melbourne: Longman Cheshire, 1983

31 Green M, Solnit AJ. Reactions to the threatened loss of a child: a vulnerable child syndrome. Pediatrics 1964; 34: 58-66.

32 Baird HW, Gordon EC. Neurological evaluation of infants and children. London: Spastics International Medical Publications, 1983.

33 Messmer MD, Schallberger U, Gattiker MD, Senning A. Psychomotor and intellectual development after deep hypothermia and circulatory arrest in early infancy. hypothermia and circulatory arrest in early

34 Myers-Vando R, Steward MS, Folkins $\mathrm{CH}$, Hines $\mathrm{P}$. The effects of congenital heart disease on cognitive development, illness causality concepts, and vulnerability Am F Orthopsychiatry 1979; 49: 617-24.

35 Linde LM, Rasof B, Dunn OJ. Longitudinal studies of intellectual and behavioral development in children with congenital heart disease. Acta Paediatr Scand 1970; 59: 169-76.

36 DeMaso DR, Beardslee WR, Silbert AR, Fyler DC. Psychological functioning in children with cyanotic heart defects. Dev Behav Pediatr 1990; 11: 289-93.

37 Linde LM, Rasof B, Dunn OJ. Attitudinal factors in congenital heart disease. Pediatrics 1966; 38: 92-101.

38 Silbert A, Wolff PH, Mayer B, Rosenthal A, Nadas AS. Cyanotic heart disease and psychological development. Pediatrics 1969; 43: 192-200.

39 Kramer HH, Awiszus D, Sterzel U, van Halteren A, Clasen $R$. Development of personality and intelligence in children with congenital heart disease. $\mathcal{f}$ Child Psychol Psychiatry 1989; 30: 299-308

40 Shampaine EL, Nadelman L, Rosenthal A, Behrendt D, Sloan H. Longtitudinal psychological assessment in tetralogy of Fallot. Pediatr Cardiol 1990; 10: 135-40.

41 Dickinson DF, Sambrooks JE. Intellectual performance in children after circulatory arrest with profound hypothermia in infancy. Arch Dis Child 1979; 54: 1-6.

42 Aisenberg RB, Rosenthal A, Nadas AS, Wolf PH. Developmental delay in infants with congenital heart Developmental delay in infants with

43 Gonzalez-Pardo L, Miles M, Taylor M. Congenital heart disease: developmental and neurological evaluation in preschool children. Fournal of the Kansas Medical Society 1981; 82: 115-8, 136.

44 Stevenson JG, Stone EF, Dillard DH. Intellectual development of children subjected to prolonged circulatory arrest during hypothermic open heart surgery. Circulation 1974 50: $54-9$.

45 Norwood WI, Dobell AR, Freed MD, et al. Intermediate results of the arterial switch repair: a 20 -institution study. 7 Thorac Cardiovasc Surg 1988; 96: 854-63.

46 Bellinger DC, Wernovsky G, Rappaport LA, et al. Cognitive development of children following repair of transposition development of children following repair of transposition
of the great arteries using deep hypothermic circulatory of the great arteries using deep
arrest. Pediatrics 1991; 87: 701-7.

47 Mendoza JC, Wilkerson SA, Reese AH. Follow up of patients who underwent arterial switch repair for transposition of the great arteries. Am F Dis Child 1991; 145 40-3. 